\title{
Evolution of seaports of the Russian Far East in relation to changes in the energy structure in Pacific Asia
}

\author{
Sergey Venevsky ${ }^{1}$ and Elena Zaostrovskikh ${ }^{2}$ \\ ${ }^{1}$ Department of Earth System Sciences, Tsinghua University, Beijing, China \\ ${ }^{2}$ Economic Research Institute FEB RAS, Khabarovsk, Russia \\ Correspondence: Sergey Venevsky (venevsky@tsinghua.edu.cn)
}

Received: 7 May 2018 - Revised: 2 August 2018 - Accepted: 6 August 2018 - Published: 10 September 2018

\begin{abstract}
We estimated the current state of seaports Vanino and Sovetskaya Gavan, situated in the Russian Far East, as beneficiaries to themselves (at local scale), to Khabarovsk Krai (regional or provincial scale) and to the Russian Federation (inter-regional or federal scale). Further, we make projections for the near future (until the year 2030) for conditions of current export fuel supply demands in China and for conditions of climate-friendly energy restructuring in China. It is shown that the coal specialization of Vanino and Sovetskaya Gavan seaports will not be profitable in the near future (year 2030) for conditions of climate-friendly energy restructuring in China. There will be considerable economic losses at the national level if coal specialization is persistent. Thus, environmental policies regarding energy structure in a country with a large economy may sufficiently influence the development of transport, industry and urban infrastructure on an inter-regional, regional or local level for a country importing fuel resources.
\end{abstract}

\section{Introduction}

It has been long anticipated by researchers and policy makers that climate-friendly restructuring in the energy sector of one country may have long-lasting consequences for the economic, social and environmental situation in another country importing fuel. The socioeconomic effects of decreasing fuel imports can have different consequences in the importing country at inter-regional (national), regional (provincial) and local scales. Represented here is a case of China's energy sector restructuring and Russian import of coal. Russia has now changed priorities due to the geopolitical situation and is now focused to the east (China, Japan, South Korea).
Coal is transported to China from Russia through seaports of the Russian Far East, particularly in Khabarovsk Krai (see Fig. 1a). The seaports of Vanino and Sovetskaya Gavan are all-year-round ports in Khabarovsk Krai (see Fig. 1b), specializing in different cargo types, but mainly coal, with catchment areas for coal mainly situated in eastern Siberia and the far eastern federal districts (see Fig. 1c). Further prospects for the development of the seaports of Vanino and Sovetskaya Gavan will primarily be connected with the Russian national project "Free Port of Vanino", which will later spread to the port of Sovetskaya Gavan. The main idea of the project is the development of industrial exports based on the potential of the Khabarovsk territory. It is expected that its implementation will modify the economy of the Khabarovsk Krai region. However, changes in export supply needs may override benefits to the province.

In this study, we focused on the seaports of Vanino and Sovetskaya Gavan as beneficiaries at different spatial scales (a) at the local scale (i.e., to themselves), (b) at regional or provincial scale (i.e., to Khabarovsk Krai) and (c) at interregional or federal scale (to the Russian Federation). Further, we make projections until the year 2030 for (a) current export fuel supply needs in China and (b) climate-friendly energy restructuring in China.

\section{Methods}

We took tax to profit, number of persons employed and investments for development of port infrastructure as optimization variables of the study. Initial data sources were Russian state Statistics and Chinese state Statistics for the years 2005-2013. 
(a)

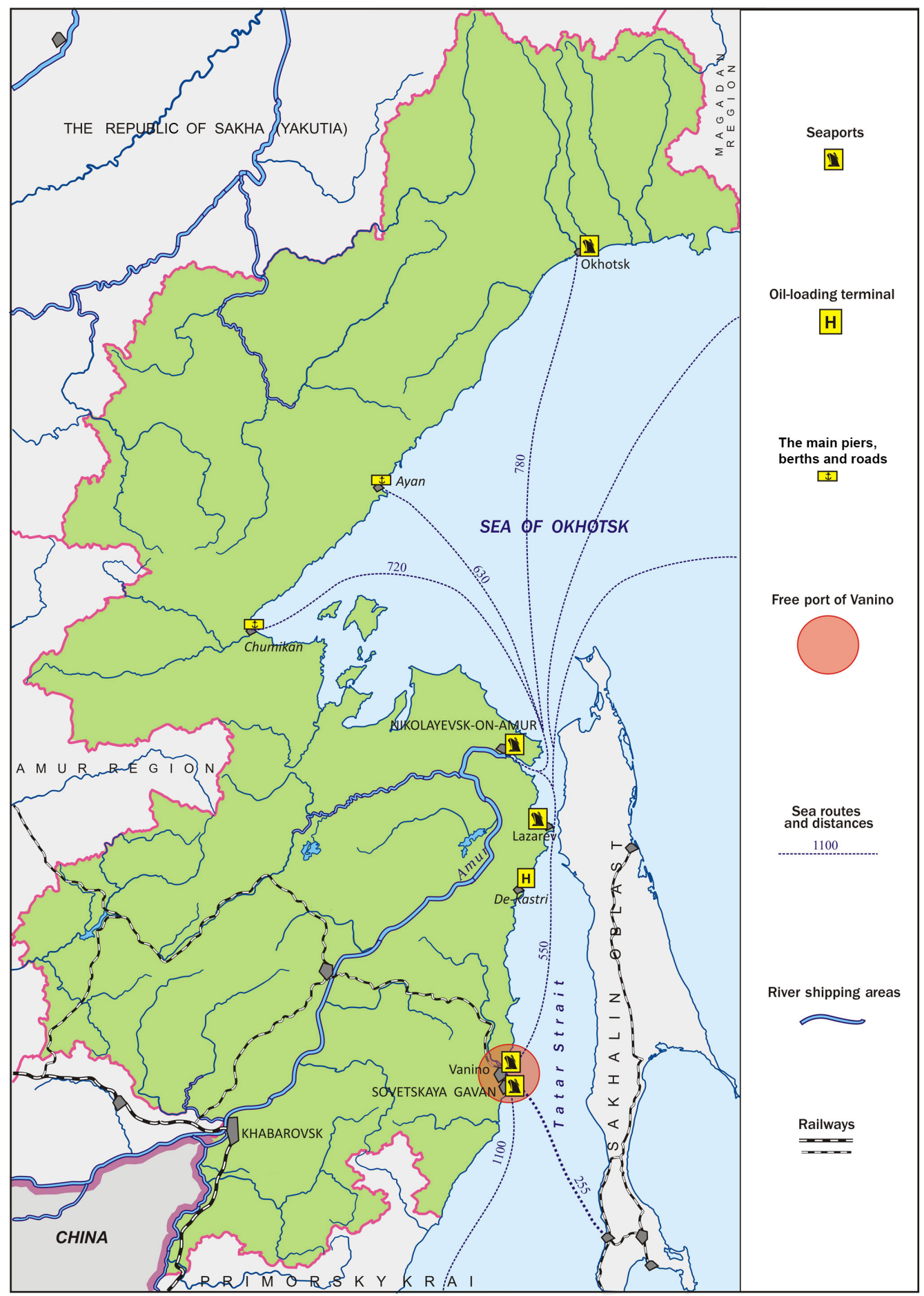

Figure 1. 
(b)

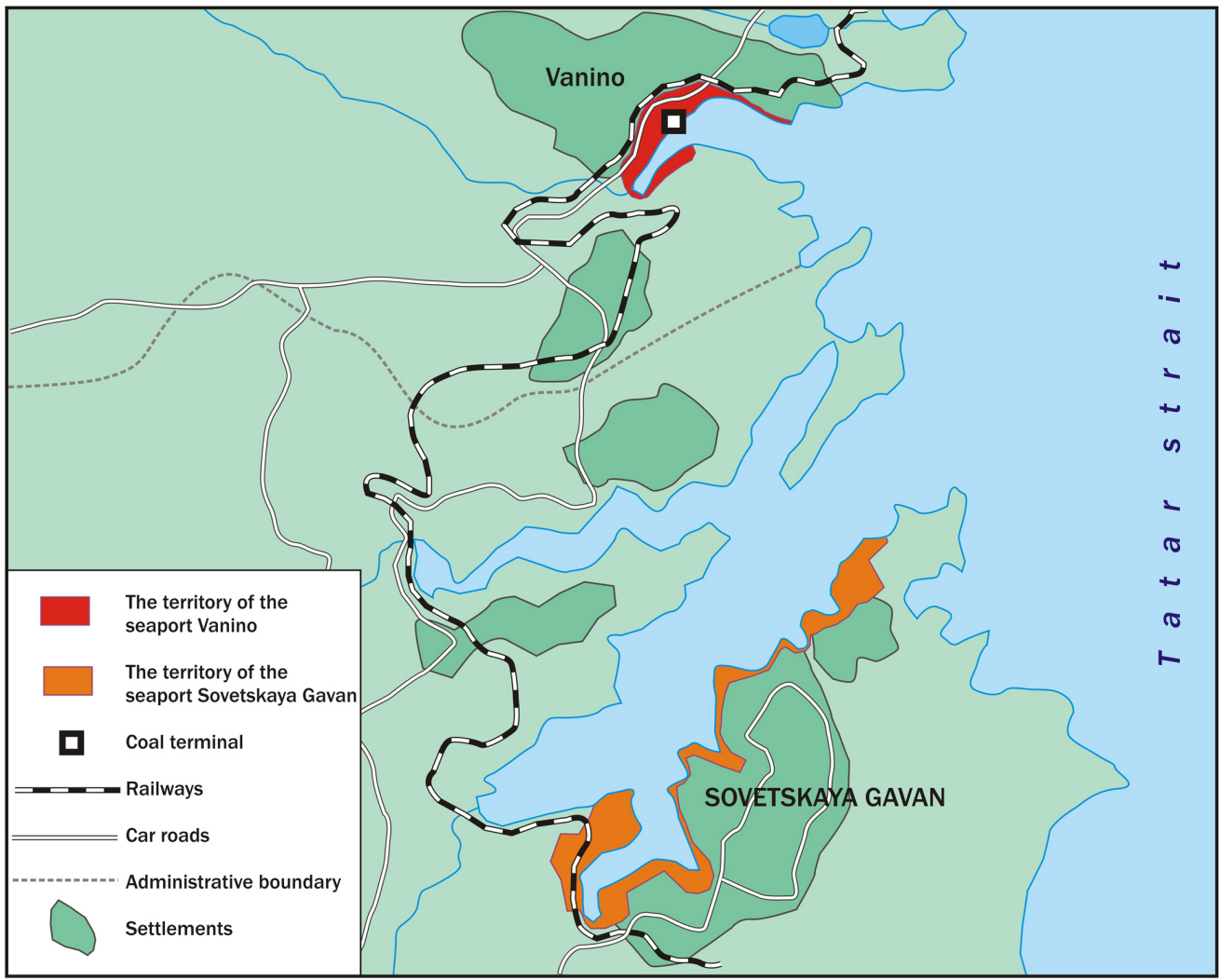

(c)

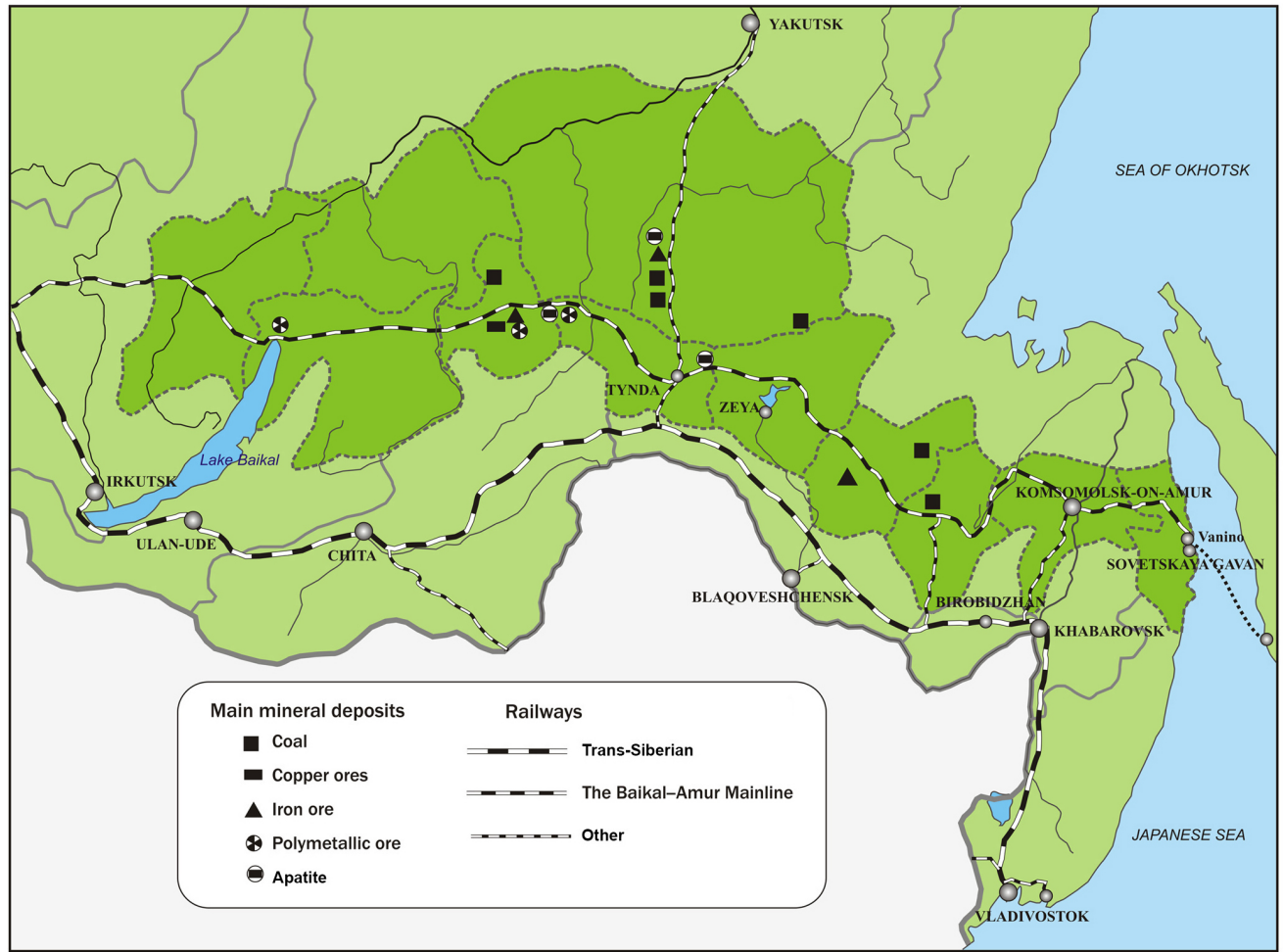

Figure 1. Geographical setting of the study: (a) seaports of the Russian Far East (distances are given in kilometers); (b) seaports of Vanino and Sovetskaya Gavan; (c) coal mining areas supplying the seaports of Vanino and Sovetskaya Gavan. 
Export supply needs for coal from Vanino and Sovetskaya Gavan were calculated from the historical need for fossil fuels in China (see Fig. 1 from Lu et al., 2018) for the years 2005-2030, which projected into the future according to current export needs from the seaports for the years 2005-2013.

Total "tax to profit" amounts for the seaports Vanino and Sovetskaya Gavan for the present were calculated for the entire cargo port throughput for categories of commodities divided into four classes: raw materials (including coal), materials, semi-finished products and equipment (Zaostrovskikh, 2017a). Costs (further recalculated to tax to profit) were estimated using matrixes of input-output commodity fluxes (separately for inter-regional, regional and port level; Zaostrovskikh, 2017a). In order to evaluate the cost parameters, all cargo was listed at 2013 prices. Population changes for the present in urban settlements around the seaports were taken from the Russian Population Census (Zaostrovskikh, 2017a).

Total tax to profit for the future for the seaports and future investments for ports' infrastructure were estimated in two scenarios: scenario 1, in which demand in China continues slightly to decrease as now and scenario 2 , in which environmental energy restructuring in China is assumed with considerable decrease in the need for coal. To estimate future total cargo in Vanino and Sovetskaya Gavan, all running investment projects were assumed to be fulfilled in the near future, 2020 (variant I), or planned new investment projects for the seaports were assumed to be accomplished up to the year 2030 at its minimum (variant II) and maximum (variant III) extent. Variant II is subdivided further into three subvariants, according to percentage of coal in the total cargo: IIa - the recent percentage of coal is assumed; IIb - half of recent percentage of coal is assumed, while the amount of other cargo types is proportionally increasing their recent values and IIc - no coal, all other cargo types substitute it. The limitations on carrying capacity for the existing railroad network were accounted for (Zaostrovskikh, 2017b). Future population dynamics was estimated using nonlinear regression for persons employed by cargo throughput.

All calculations were performed in Microsoft Excel using macros.

State variables of our model are cargo throughput (millions of tonnes in four different categories for inter-regional, Khabarovsk Krai and ports of Vanino and Sovetskaya Gavan:

$\mathrm{CARGO}_{i}($ total $)=\sum_{i=1}^{4} \mathrm{CARGO}_{l}(i)$,

where $l$ are either inter-regional (IR), Khabarovsk Krai (KK) or the ports (P) throughout and $i$ is a type of material: raw materials (including coal), materials, semi-finished products or equipment. Current day raw materials are completely associated with coal in our model, and for the future period in variant IIb we assume that half of the coal will be substituted by other raw materials. Coal cargo throughput in all categories $l$ is assumed to be a function of total coal demand (billions of tonnes) for China $D(t)=D(2005) \cdot f(t)$, where function $f(t)$ is normalized to its minimum ratio of coal in total country's energy consumption. The function can have a linear growth in the interval 2005-2030 when the existing trend of coal demand is assumed or it can have a maximum around 2020 and decreasing trend afterwards if the climatefriendly restructuring of energy consumption in China is assumed.

Cargo throughput in all categories is supposed to be limited by carrying capacities of transport lines (railway and automobile for inter-regional and the Khabarovsk Krai categories) and the port infrastructure facilities:

$\mathrm{CARGO}_{l}(i) \leq 12 \cdot \mathrm{CPM}_{l}(i)$,

where $\mathrm{CPM}_{l}(i)$ are monthly carrying capacities for infrastructure of different categories and different commodity types (million tonnes per month). Carrying capacities for the future period are dependent on annual investment functions $F(I(t))$ according to scenarios (see description above), so that

$\mathrm{CPM}_{l}(i)(t)=\mathrm{CPM}_{l}(i)(2015) \cdot F(I(t))$,

where $F(I(2015))=1$ and $I($ total $)=\sum_{2015}^{2030} I(t)$ is the total investment (in millions of rubles) according to the adopted scenario.

Cargo throughput is recalculated into the cost for processing of commodities (millions of rubles) for category $\mathrm{P}$, and tax to profit for categories IR and KK, using prices for the year 2013.

Number of employed people (in units of thousands of people) for the future period for the three different categories (IR, KK and $\mathrm{P}$ ) was calculated from a log-linear regression functions $N_{l}=a_{l} \cdot \exp \left(b_{l} \cdot \mathrm{CARGO}_{l}\right.$ (total), $a$ and $b$ are regression coefficients), obtained from Russian state Statistics and the Russian Population Census for the years 2005-2015.

The model was calibrated for the year 2005 and validated for the years 2013 and 2015 using Russian state Statistics.

\section{Results}

The calculated current state of seaports Vanino and Sovetskaya Gavan as beneficiaries to themselves, to Khabarovsk Krai and to the Russian Federation is shown in Table 1. Based on the estimates received, the following conclusion can be drawn: the cargo turnover of the Vanino and Sovetskaya Gavan seaports by natural indicators is developing at a more intensive rate ( 3 times) than the value ( 2.16 times) for the period 2005-2013. This occurs because the largest share is for raw materials (coal) and in terms of value on materials (oil products). It follows that the construction of the coal terminal in the year 2005 ensured a stable loading of the port of Vanino, but at the same time did not create the expected economic effect neither for the seaports nor for the economy of 
Table 1. Current state of seaports Vanino and Sovetskaya Gavan as beneficiaries to themselves, to Khabarovsk Krai and to the Russian Federation

\begin{tabular}{lrrr}
\hline Seaports Vanino and Sovetskaya Gavan & 2005 & 2009 & 2013 \\
\hline Cargo (millions of tonnes) & 0.9 & 0.8 & 2.7 \\
Raw materials & 0.3 & - & - \\
Materials & 0.6 & 0.8 & 2.7 \\
Profit from cargo processing (millions of rubles) & 1484.4 & 2637.3 & 3204.6 \\
Employed (thousands of people) & 3.1 & 2.8 & 2.5 \\
\hline Khabarovsk Krai & & & \\
\hline Cargo (millions of tonnes) & 3.4 & 2.2 & 1.9 \\
Raw materials & 2.2 & 1.3 & 1.1 \\
Equipment & 1.2 & 0.8 & 0.8 \\
Employed (thousands or people) & 9.8 & 7.3 & 6.9 \\
Tax to profit, regional income (millions of rubles) & 106.9 & 189.8 & 230.7 \\
\hline Other Russian regions & & & \\
\hline Cargo (millions of tonnes) & 2.9 & 10.0 & 35.6 \\
Raw materials & 0.3 & 6.5 & 33.7 \\
Coal & 0.3 & 6.5 & 33.7 \\
Materials & 2.5 & 3.5 & 2.6 \\
Employed (thousands of people) & 4.2 & 7.6 & 22.4 \\
Tax to profit, federal income (millions of rubles) & 11.8 & 21.0 & 25.6 \\
\hline
\end{tabular}

Table 2. Future state of seaports Vanino and Sovetskaya Gavan as beneficiaries to themselves, to Khabarovsk Krai and to the Russian Federation. Bold font indicates cases of environmental energy restructuring with a considerable decrease in coal demand in China.

\begin{tabular}{lrrrr}
\hline Variants of development & \multicolumn{3}{c}{2030} \\
\cline { 2 - 5 } & I & IIa & IIb & IIc \\
\hline Seaports Vanino and Sovetskaya Gavan & & & & \\
\hline Cargo (millions of tonnes) & 2.8 & 3.9 & 13.2 & 14.0 \\
Materials & 2.8 & 3.9 & 13.2 & 14.0 \\
Profit from cargo processing (millions of rubles) & 5515.8 & 6408.3 & 8619.6 & 9963.1 \\
Employed (thousands of people) & 3.1 & 3.8 & 4.2 & 4.4 \\
Investments for ports (billions of rubles) & 21.5 & 49.2 & 42.6 & 44.0 \\
\hline Khabarovsk Krai & & & & \\
\hline Cargo (millions of tonnes) & 4.4 & 3.1 & 10.6 & $15.5 / \mathbf{1 5 . 3}$ \\
Raw materials & - & - & - & $4.9 / \mathbf{4 . 7 7}$ \\
Equipment & 2.5 & 3.1 & 10.6 & 10.6 \\
Employed (thousands of people) & 7.3 & 7.4 & 9.9 & $13.4 / \mathbf{1 3 . 2}$ \\
Tax to profit, regional income (millions of rubles) & 297.8 & 364.0 & 465.4 & $538.0 / \mathbf{5 2 4}$ \\
\hline Other Russian regions & & & & \\
\hline Cargo (millions of tonnes) & & & & \\
Raw materials & $35.6 / \mathbf{2 3 . 8}$ & $45.9 / \mathbf{3 1 . 1}$ & $29.1 / \mathbf{2 2 . 5}$ & $23.3 / \mathbf{2 2 . 5}$ \\
Coal & $33.7 / \mathbf{2 1 . 2}$ & $43.4 / \mathbf{2 8 . 3}$ & $18.5 / \mathbf{1 2}$ & $14.1 / \mathbf{1 3 . 3}$ \\
Materials & $33.7 / \mathbf{2 1 . 2}$ & $40.8 / 25.7$ & $17.5 / \mathbf{1 1}$ & $2.1 / \mathbf{1 . 3}$ \\
Employed (thousands of people) & 2.6 & 2.4 & 10.5 & 9.2 \\
Tax to profit, federal income (millions of rubles) & $33.1 / 22$ & $20.4 / \mathbf{1 5 . 3}$ & $51.7 / \mathbf{3 9 . 2}$ & $59.7 / \mathbf{5 4 . 6}$ \\
\hline
\end{tabular}


the Khabarovsk territory, nor for other regions of the Russian Federation (see Table 1). In addition, with the technological development of the port of Vanino, the number of jobs decreased by $33 \%$ (see Table 1), and the ecology of the adjoining territory and the water area of the Vanino seaport also deteriorated.

As a result, the "coal orientation" of the port of Vanino has made it dependent on changes in East Asian (especially Chinese) fuel and energy resource markets, which is seen in our projections for the future.

Indeed, this can be seen from the estimated future state of seaports Vanino and Sovetskaya Gavan as beneficiaries to themselves, to Khabarovsk Krai and to the Russian Federation (see Table 2), after application of cuts in cargo throughput and tax to profit (values in red in Table 2), caused by application of scenario 2 (environmental energy restructuring with considerable decrease in coal demand in China). Thus, implementation of variant III, assuming to keep coal cargo at maximum and accomplishment of investment projects related to the transportation infrastructure development to maximum is becoming unprofitable because investments will be too high and tax to profit amounts for the Russian Federation will be almost the same as for the less ambitious and twice cheaper variant IIb (see Table 2).

\section{Conclusions and discussion}

It is shown that the coal specialization of Vanino and Sovetskaya Gavan seaport will not be economically beneficial in the near future (year 2030) in conditions of climate-friendly energy restructuring in China. Despite no (or almost no) losses at local (port) and regional (Khabarovsk Krai) levels, at the inter-regional (national) level there will be considerable losses if the coal specialization is persistent. Even considerable investment cannot increase the amount of federal tax to profit if the restructuring of cargo to finished goods other than coal is not done in the seaports of Vanino and Sovetskaya Gavan.

Thus, environmental policies regarding the energy structure in a large economy may sufficiently influence development of transport, industry and urban infrastructure on an inter-regional, regional and local level for a country importing fuel resources. Elaboration of optimal socioeconomic strategies is necessary for an inter-regional (national), regional (provincial) and local (port) level to adapt to climatefriendly energy restructuring in an exporting country. Such strategies should be based on quantitative spatial and temporal scenarios of industrial and transportation development at the three levels as a response to changing external demands for fossil fuels.
Data availability. Raw input data are the property of the Russian Statistic Agency (RSA) and can be obtained from the authors with the permission of the RSA.

Author contributions. The authors contributed equally to the design of the study, the calculations and the writing of paper.

Competing interests. The authors declare that they have no conflict of interest.

Special issue statement. This article is part of the special issue "European Geosciences Union General Assembly 2018, EGU Division Energy, Resources \& Environment (ERE)". It is a result of the EGU General Assembly 2018, Vienna, Austria, 8-13 April 2018.

Acknowledgements. This work was supported by the National Natural Science Foundation of China (31570475).

Edited by: Michael Kühn

Reviewed by: Lidibert Gonzalez-Gonzalez and one anonymous referee

\section{References}

Lu, C., Venevsky, S., and Cao, S.: The effects of the China-Russia gas deal on energy consumption, carbon emission, and 1 particulate matter pollution in China, NPJ Atmospheric and Climate Science, 1, 8, https://doi.org/10.1038/s41612-018-0018-8, 2018.

Zaostrovskikh, E. A.: Transport and industrial hub in VaninoSovetskaya Gavan: potential formation of growth poles, Power and administration in the East of Russia, 1, 35-43, 2017a.

Zaostrovskikh, E. A.: Seaports of the Khabarovsk territory as poles of economic growth, Spatial Economics, 4, 170-183, $2017 \mathrm{~b}$. 